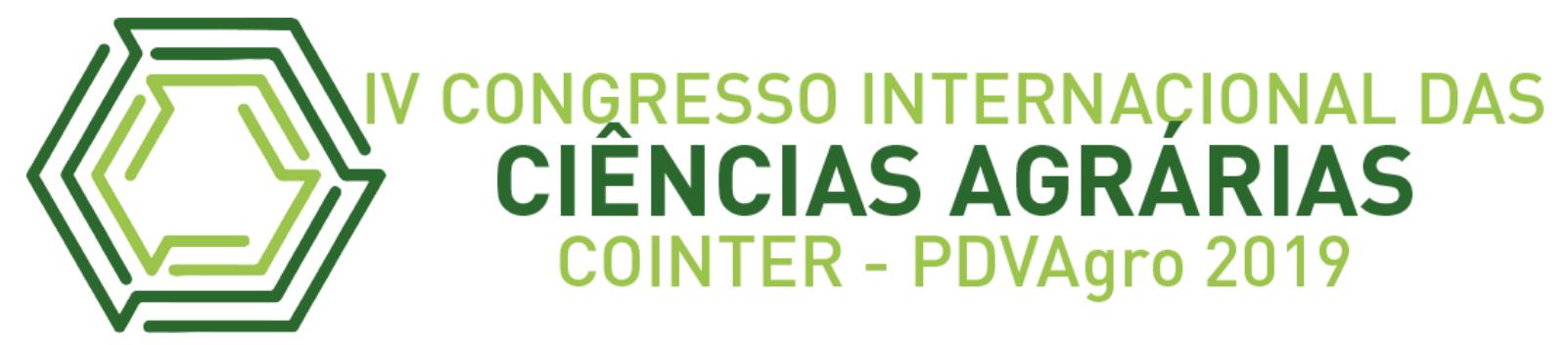

Apresentação: Comunicação Oral

Davila Esmelinda Oliveira Silva ${ }^{1}$; Daniele Muniz dos Reis ${ }^{2}$; Danilo Costa dos Santos ${ }^{3}$

Caroline de Sousa Ribeiro ${ }^{4}$; Antonio Alisson Fernandes Simplicio ${ }^{5}$

\title{
Reaproveitamento de resíduos alimentares do restaurante do IFMA campus Codó na formação de adubo orgânico para produção de pepinos (Cucumis sativus, L.)
}

\section{Food waste reuse at IFMA campus Codó restaurant in the formation of organic fertilizer for cucumber production (Cucumis sativus, $L$.)}

DOI: $\underline{\text { https://doi.org/10.31692/2526-7701.IVCOINTERPDVAgro.2019.0093 }}$

\begin{abstract}
Resumo
O respectivo trabalho visa reaproveitar uma grande quantidade de resíduos alimentares que é produzido diariamente pelo restaurante do Instituto Federal de Educação, Ciência e Tecnologia do Maranhão - IFMA campus Codó, esse restaurante desempenha um papel importante dentro instituto, pois oferta refeições prontas e saudáveis. Contudo, observa-se que existe uma grande quantidade de restos alimentares, caracterizando assim o desperdício. Porém, a maioria das sobras desses alimentos são descartados de maneira incorreta e não são reutilizados. Com a finalidade de reaproveitar esses restos alimentares, foi elaborado um composto orgânico a partir desse material descartado. Processo esse que consiste na decomposição dos restos alimentares

\footnotetext{
${ }^{1}$ Bacharelado em Agronomia , Instituto federal de educação, ciência e tecnologia do maranhão-campus Codó, davilaoliveira04@hotmail.com

${ }^{2}$ Bacharelado em Agronomia, Instituto federal de educação, ciência e tecnologia do maranhão-campus Codó, danielemdosreis@gmail.com

${ }^{3}$ Licenciatura em Quimica, Instituto federal de educação, ciência e tecnologia do maranhão-campus Codó, danylo.santos25681@gmail.com

${ }^{4}$ Bacharelado em Agronomia, Instituto federal de educação, ciência e tecnologia do maranhão-campus Codó, carolineribeiro629@gmail.com.

5 Mestre, Instituto Federal de educação, ciência e tecnologia do maranhão-campus Codó, antonio.simplicio@ifma.edu.br
} 
por meio de microrganismos decompositores. Além disso, visando um composto de qualidade, foi necessário combinar resíduos ricos em carbono, como os capins, com outros materiais ricos em nitrogênio, como palhada de restos de culturas e estercos animais. Objetivando avaliar a potencialidade desse composto sobre os demais substratos testados e aplicados na produção de frutos de pepino (Cucumis sativus, L.), cultivados em covas, com delineamento em blocos casualizados, além de 4 tratamentos com 12 repetições cada, sendo eles: E1 (esterco de bode), E2 (húmus de palmeiras), E3 (Composto orgânico) e E4 (testemunha), dentre as avaliações feitas, tais como: quantidade de folhas, diâmetro da raiz, diâmetro do caule, comprimento da raiz, comprimento do caule e brotamento, ressaltando ainda que a avaliação foi baseada no teste de comparação de medias ( teste tukey). A partir do resultado desse teste pode-se observar que o composto orgânico teve um maior desenvolvimento comparando-o com os outros substratos usados no plantio do pepino(Cucumis sativus, L.).

Palavra-chave: Adubação de hortaliças. Compostagem. Reciclar

\begin{abstract}
Its work aims to reuse a large amount of food waste that is produced daily by the restaurant of the Federal Institute of Education, Science and Technology of Maranhão - IFMA campus Codó, this restaurant plays an important role within the institute, as it offers ready and healthy meals. However, it is observed that there is a large amount of food waste, thus characterizing the waste. However, most of the leftovers from these foods are incorrectly discarded and not reused. In order to reuse these food waste, an organic compound was prepared from this discarded material. This process consists in the decomposition of food waste by decomposing microorganisms. In addition, for a quality compost, it was necessary to combine carbon-rich residues, such as grass, with other nitrogen-rich materials, such as crop residues and animal manure. Aiming to evaluate the potential of this compound on the other substrates tested and applied in the production of cucumber fruits (Cucumis sativus, L.), cultivated in pits, with randomized block design, in addition to 4 treatments with 12 replications each: E1 (goat manure), E2 (palm humus), E3 (Organic compost) and E4 (control), among the evaluations made, such as: leaf quantity, root diameter, stem diameter, root length, stem length. stem and budding, emphasizing that the evaluation was based on the mean comparison test (tukey test). From the result of this test it can be observed that the organic compost had a better development comparing it with the other substrates used in the cucumber (Cucumis sativus, L.) planting.
\end{abstract}

Keyword: Fertilization of vegetables. Composting. Recycle 


\section{INTRODUÇÃO}

O desaproveitameto de alimentos no Brasil coloca o país na $10^{\mathrm{a}}$ posição no ranking dos países que mais desperdiçam alimentos no mundo. O desperdício de alimentos chega a 35\% da produção agrícola anual, quantidade suficiente para alimentar 10 milhões de pessoas (GOULART, 2008).

O conceito de desperdício é característico e inerente a todos os sistemas naturais sendo, no entanto, substancialmente potenciado, a nível global, pela atividade humana. Desperdiçar diz respeito a não utilizar, ou subaproveitar, parte dos recursos disponíveis e mobilizados para uma determinada atividade. A sobra de alimentos é inevitável, deve-se seguir rigorosamente alguns critérios técnicos, como treinamento da equipe e monitoramento do processo de produção de forma a poder aproveitá-las (SILVA JÚNIOR; TEIXEIRA, 2007).

O não aproveitamento dessas sobras caracteriza como lixo orgânico, pois o destino equivocado desse lixo pode trazer sérias consequências indesejáveis aos seres humanos, como proliferação de insetos, ratos, bactérias e fungos (PLANETA SUSTENTÁVEL, 2010).

O lixo orgânico, muitas vezes, é descartado em lixões, ruas, rios e matas, poluindo o meio ambiente, visto que, o acúmulo de resíduos orgânicos a céu aberto favorece o desenvolvimento de bactérias, vermes e fungos que causam doenças nos seres humanos. Além disso, favorece o desenvolvimento de insetos, ratos e outros animais que podem transmitir doenças aos homens.

Uma boa utilidade do lixo orgânico é a produção de adubo orgânico, muito usado na agricultura, através do processo de compostagem a reciclagem dos resíduos orgânicos é processada pela ação dos microrganismos presentes nos mesmos, os quais são responsáveis pela decomposição e/ou estabilização biológica da matéria orgânica, para transformá-la em compostos e húmus (MANO et al., 2010).

O termo compostagem está associado ao processo de tratamento dos resíduos orgânicos sejam eles de origem urbana, industrial, agrícola e florestal, a compostagem consiste em um procedimento de decomposição e estabilização biológica dos substratos orgânicos sob condições que favorecem o desenvolvimento de temperaturas termofílicas que resultam da 
produção biológica de calor transformando em um composto fertilizante que pode ser utilizado como nutriente na produção de olerícolas (OLIVEIRA; SARTORI; GARCEZ, 2008).

O pepino (Cucumis sativus L.) originário da Índia, pertence à família das cucurbitáceas. É uma hortaliça de clima tropical, que melhor se desenvolve e produz sob temperaturas na faixa de 20-30 ${ }^{\circ} \mathrm{C}$. Essa hortaliça tem crescido de importância na comercialização, sendo muito apreciado e consumido em todo Brasil, na forma crua de seu fruto imaturo em saladas, curtido em salmoura ou vinagre e raramente maduro e cozido. Em 1998, foram comercializadas 34.508 toneladas na CEAGESP (FNP CONSULTORIA e COMÉRCIO, 2000).

A planta é herbácea, anual e com hastes longas. O hábito de crescimento é indeterminado e a planta desenvolve-se no sentido vertical ou prostrado, dependendo da presença ou ausência de suporte. As hastes apresentam gavinhas, que se fixam a qualquer tipo de suporte (FILGUEIRA, 2008), apud. SIRTOLI (2010). Seguindo os estudos de Filgueira (2008) apud Sirtoli,(2010), o fruto de pepino caipira é tipicamente alongado, estreito, com 20$30 \mathrm{~cm}$ de comprimento, de cor verde escura, triloculares e com acúleos brancos. Com um sabor típico e agradável, os frutos são de bastante aceitação em grandes mercados.

Este trabalho teve por objetivo reaproveitar os restos alimentares do restaurante do IFMA campus-Codó, transformando-o em composto orgânico para posterior avaliação da potencialidade do mesmo entre os demais substratos usados no cultivo de pepino do tipo caipira.

\section{FUNDAMENTAÇÃO TEÓRICA}

\section{O desperdício de alimento}

Muitas vezes usados como sinônimos, os termos perdas e desperdício apresentam diferenças intrínsecas em suas definições. Como estabelece a FAO, a perda de alimentos (food loss) refere-se à redução do volume ou do valor nutricional (qualidade) dos alimentos produzidos para consumo humano, enquanto desperdício (food waste) abrange o rejeito de alimentos.

O desperdício ocorre também quando não há planejamento adequado do volume de refeições a ser preparado. O número de comensais, o cardápio do dia e até mesmo a estação 
climática, devem ser considerados antes de ser definida a quantidade de alimento a ser preparada, a fim de evitar sobras (RICARTE; MOURA FÉ; SANTOS; LOPES, 2008).

No caso dos restaurantes de institutos o desperdício se mostra bastante significativo e pode ser observado dentro dos lixos e na devolução das bandejas de refeição (BRADACZ, 2003). Questões como o número de frequentadores, o cardápio do dia e até mesmo a estação climática, devem ser consideradas antes de ser definida a quantidade de alimento a ser preparada, a fim de evitar sobras (SILVA JUNIOR; TEIXEIRA, 2000).

É válido ressaltar que existe uma diferença entre sobra e resto. O primeiro se trata de alimentos produzidos e não distribuídos, enquanto o segundo é definido como a quantidade de alimentos devolvida na bandeja pelo consumidor (MÜLLER, 2008). Esta perda alimentar é denominada resto ingesta, ou seja, aquele alimento que não pode mais ser aproveitado. $\mathrm{O}$ percentual de resto ingesta representa a quantidade de resto em relação à quantidade de alimentos produzidos e distribuídos e deve manter-se abaixo de 10\% (CASTRO et. al., 2003).

\section{Reaproveitamento de resíduos orgânicos (Compostagem)}

A compostagem pode ser definida como um processo aeróbio controlado, desenvolvido por microrganismos, e efetuada em duas fases distintas: a primeira é quando ocorrem as reações bioquímicas mais intensas, já a segunda fase ou fase de maturação, é quando ocorre o processo de humificação.

Processo biológico de transformação de resíduos orgânicos em substância húmicas, em outras palavras, a partir da mistura de restos de alimentos, frutos, folhas, estercos, palhadas, dentre outros, obtêm-se, no final do processo, um adubo orgânico homogêneo, de cor escura, estável, solto, pronto para ser usado em qualquer cultura, sem causar dano e proporcionando uma melhoria nas propriedades físicas, químicas e biológicas do solo (SOUZA et al., 2001).

No método de compostagem a energia produzida pelos microrganismos promove um incremento de temperaturas. Quando essas encontram-se superiores a $40^{\circ} \mathrm{C}$ começam a predominar os microrganismos termofílicos, responsáveis pela decomposição acelerada da matéria orgânica (OLIVEIRA; SARTORI; GARCEZ, 2008).

O termo compostagem diz respeito a decomposição, porém está associada com a manipulação de todo material orgânico feita pelo homem, que através da observação do que 
acontecia na natureza desenvolveu técnicas para acelerar a decomposição e produzir compostos orgânicos que atendessem rapidamente as suas necessidades.

A adubação química é uma pratica agrícola que traz resultados satisfatórios em termo de produtividade e mantém estável a temperatura e o nível de acidez do solo, dificulta ou impede a germinação de sementes de plantas invasoras, e ativa a reprodução de microrganismos benéficos às culturas agrícolas (EMBRAPA, 2007).

\section{Aplicação na cultura do pepino (Cucumis sativus, $L$.)}

A cultura do pepino apresentou na última década, na região sul do Brasil, significativo aumento quanto a área plantada, volume de produção e comercialização.

No Brasil o pepino (Cucumis sativus L.) ocupa a segunda posição em volume de produção em cultivo protegido (estufas plásticas) (SILVA et al., 1995). E sua comercialização tem obtido crescimento na importância entre as hortaliças, sendo muito apreciado e consumido em todo Brasil (NOMURA \& CARDOSO, 2000; CARDOSO, 2002).

Sendo produto perecível e consumido in natura, a preocupação com a qualidade nutricional do pepino deve ser mantida em todos os seguimentos envolvidos no processo da produção e comercialização. Segundo Carvalho, (2013) "O pepino (Cucumis sativus L.) tem grande importância econômica e social dentro do agronegócio de hortaliças no Brasil. " É muito popular e usado em todo o país. O fruto pode ser aproveitado de várias maneiras na culinária. Segundo Carvalho, (2013) “Além disto, pode ser utilizado em cosméticos e medicamentos devido a suas propriedades nutracêuticas. "

Conforme aponta Cañizares (1998), em suas pesquisas que na maioria das vezes o pepino apresenta hábitos de crescimento indeterminado, tendo o bambu como suporte vertical condutor ou fitilhos de plásticos. Suas ramas podem chegar até 3 metros de comprimento, com folhas alternadas, gavinhas, ásperas e de coloração verde escura. Possuindo o sistema radicular superficial axial, alcançando aproximadamente $30 \mathrm{~cm}$ de profundidade. 


\section{MATERIAIS E METODOS}

O presente estudo foi realizado pelo Instituto Federal de Educação, Ciência e Tecnologia do Maranhão - IFMA Campus Codó, onde decorreu a coleta de um material contendo restos alimentares vindos do restaurante do IFMA-Campus Codó, o mesmo ainda foi pesado diariamente no período de quatro semanas, essa coleta aconteceu todos os dias no horário de encerramento das atividades do restaurante que são exatamente ás 20:00 horas, o material recolhido foi armazenado em sacos de plástico e transportado com carrinho de mão para a área onde foi feito execução do projeto, após a chegada ocorreu a seleção desse material descartando-o que não irá ser utilizado na compostagem, tais como: ossos, e restos de frutas cítricas conforme demonstrado logo abaixo na figura 1.

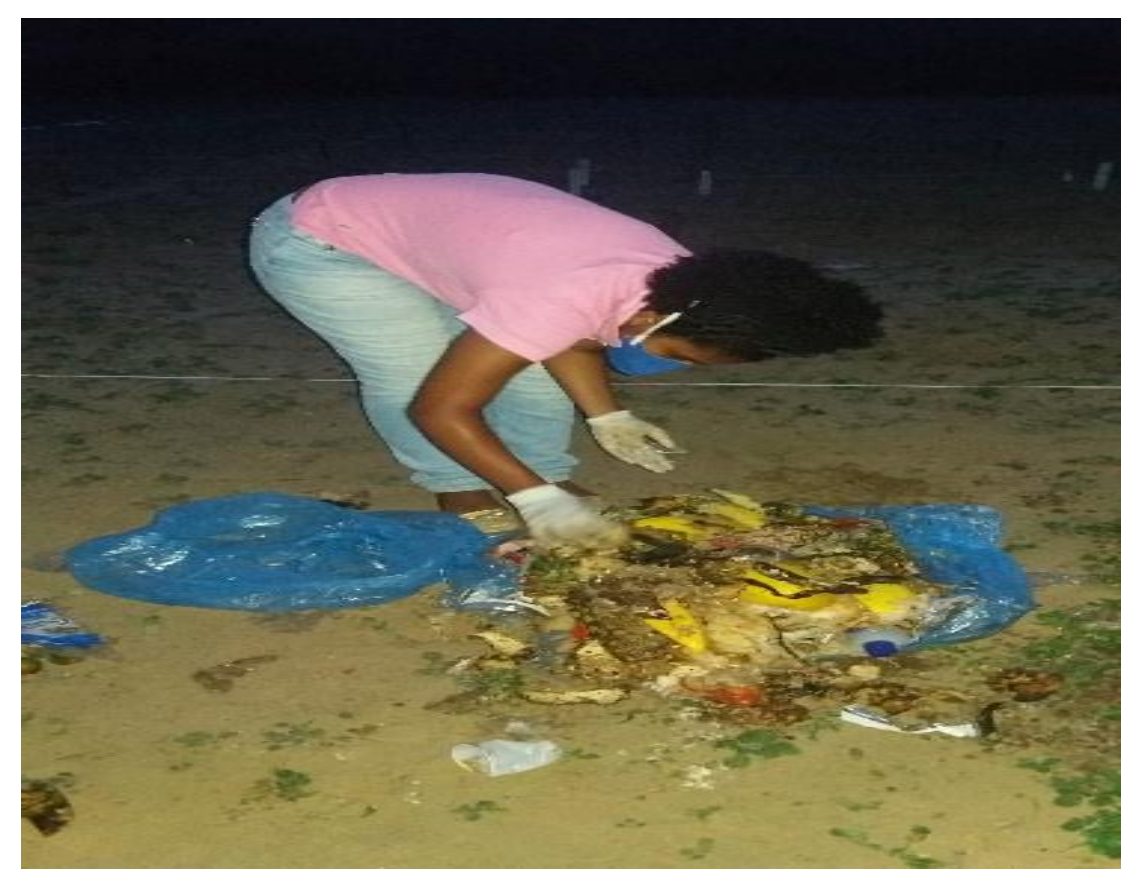

Fig.1: Separação do material. Fonte: Própria

Foi utilizado também restos de culturas (feijão, milho e graminhas) e estercos de caprino, ás culturas como milho e feijão serão recolhidas nas propriedades de alguns pequenos produtores rurais do povoado Santa Barbara que fica localizado nas proximidades do IFMACampus Codó, e serão armazenados em sacos de fibra e deslocados ao instituto, já os estercos 
e as graminhas foram coletados no próprio Instituto com auxílio de um carrinho de mão e foram armazenados no local da compostagem.

A preparação do composto foi feita em camadas, no método de Kiehl, que consiste na montagem do composto feito em manilhas (rodas de concreto) espalhando na manilha uma camada de restos de culturas (milho, feijão, gramíneas) e o material recolhido do restaurante do IFMA campus Codó até atingir a altura de $20 \mathrm{~cm}$, e em seguida foi molhada essa $1^{\circ}$ camada evitando o encharcamento, já para a $2^{\circ}$ camada espalha-se o esterco em uma altura de $5 \mathrm{~cm}$ e molha-se novamente as camadas, repete-se a operação até quando a pilha atingir a altura média de 1 metro .

Ocorreu um reviramento periódico das pilhas toda semana, para que a temperatura chegue ao ideal e acelere o processo de decomposição. A medida da temperatura será obtida através de uma barra de ferro de 1,5 metros, introduzida até o centro da pilha por 30 minutos, ao retirá-la será feita a medição da temperatura pelo tato, essa ação será feita durante o tempo de 30 a 60 dias, fato esse exposto nas figuras 2 e 3.

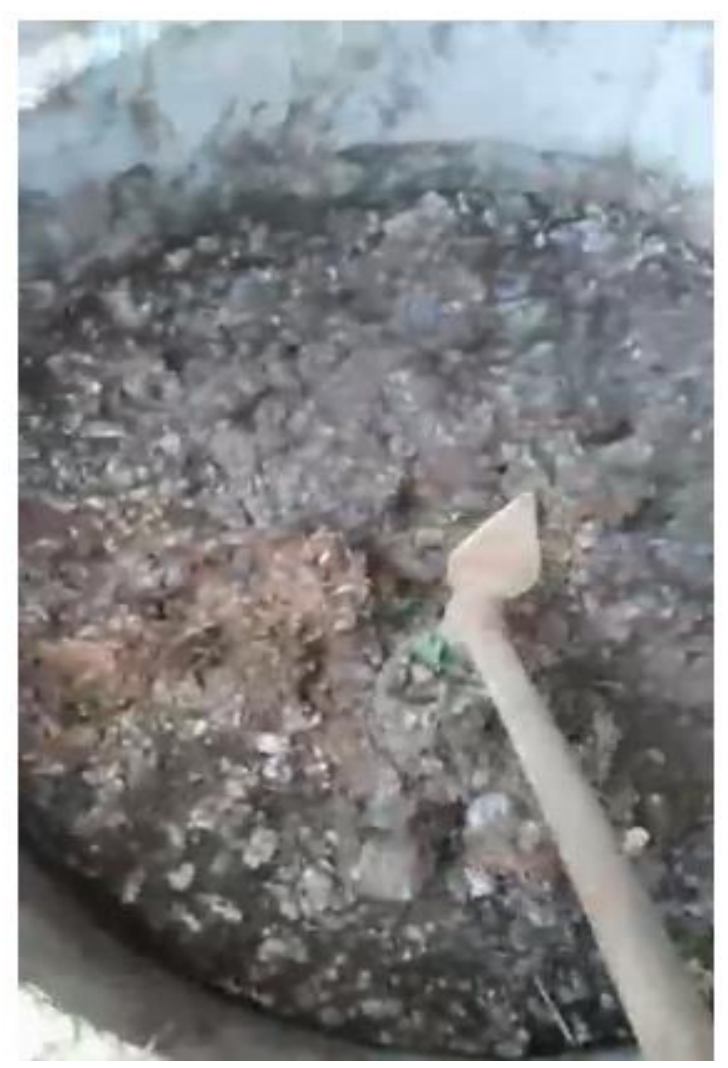

Fig 2:Reviramento Fonte: Própria

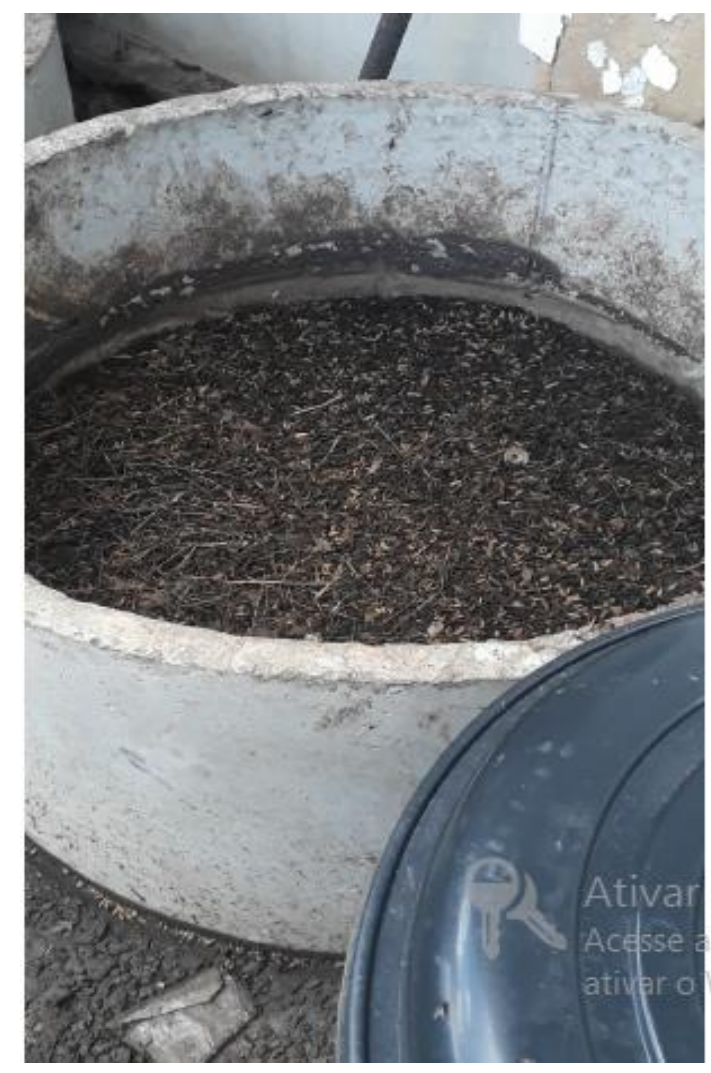

Fig. 3: Composto após 40 dias Fonte: Própria 
O delineamento experimental adotado foi o de blocos casualizados, onde foi utilizado 4 tratamentos com 12 repetições, ambos descritos nas figuras 4, pode-se observar na figura 5 o crescimento das folhas do pepineiro após 15 dias do plantio, nessa mesma época foi realizado o desbaste das plantas, e de acordo com a figura 6 observa-se o alongamento do caule e das folhas após 30 dias do plantio.

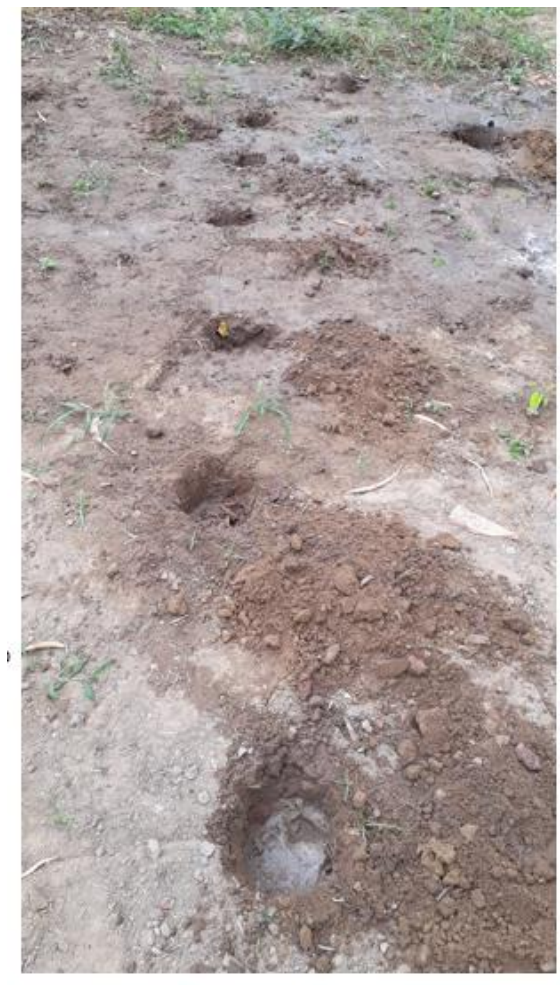

Fig.4: Abertura das covas. Fonte: Própria

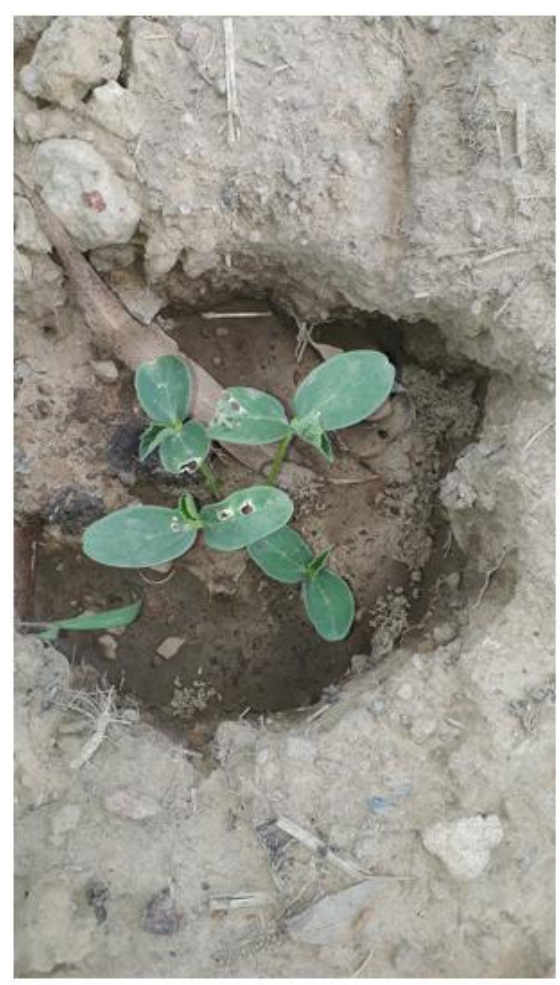

Fig.5: 15 dias após semeadura. Fonte: Própria

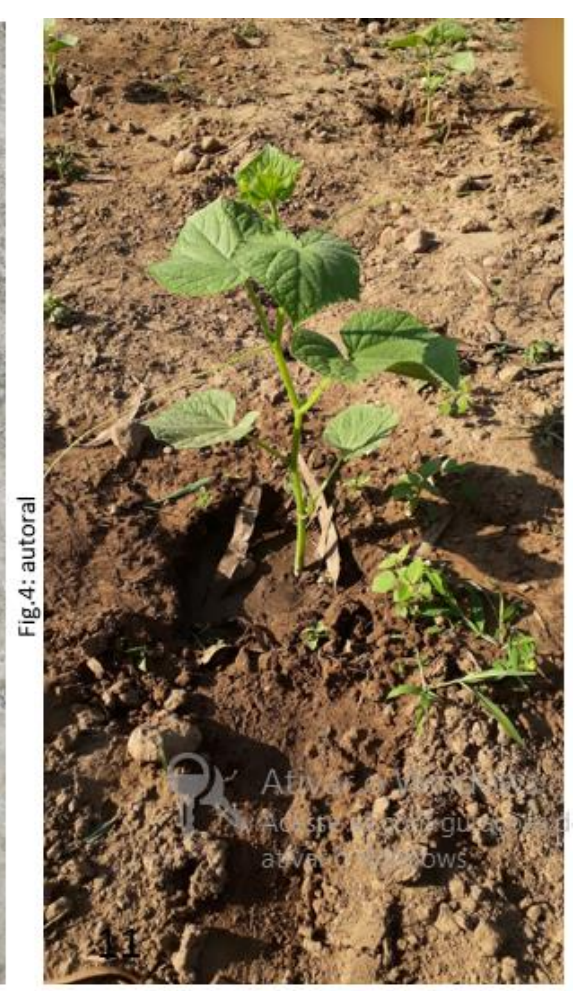

Fig.6: 30 dias após a semeadura. Fonte: Própria

O espaçamento utilizado entre as covas fora de 1 metro entre linhas e $80 \mathrm{~cm}$ entre plantas, onde o T1 foi composto orgânico, T2 humus de palmeira, T3 esterco de bode e T4 testemunha, a semeadura direta foi feita 10 dias após o preparo das covas com substratos, com 35 dias após o plantio coletou-se as plantas centrais (observa-se na figura 8) para as análises das partes aérea e da raiz de acordo com a figura 7. 


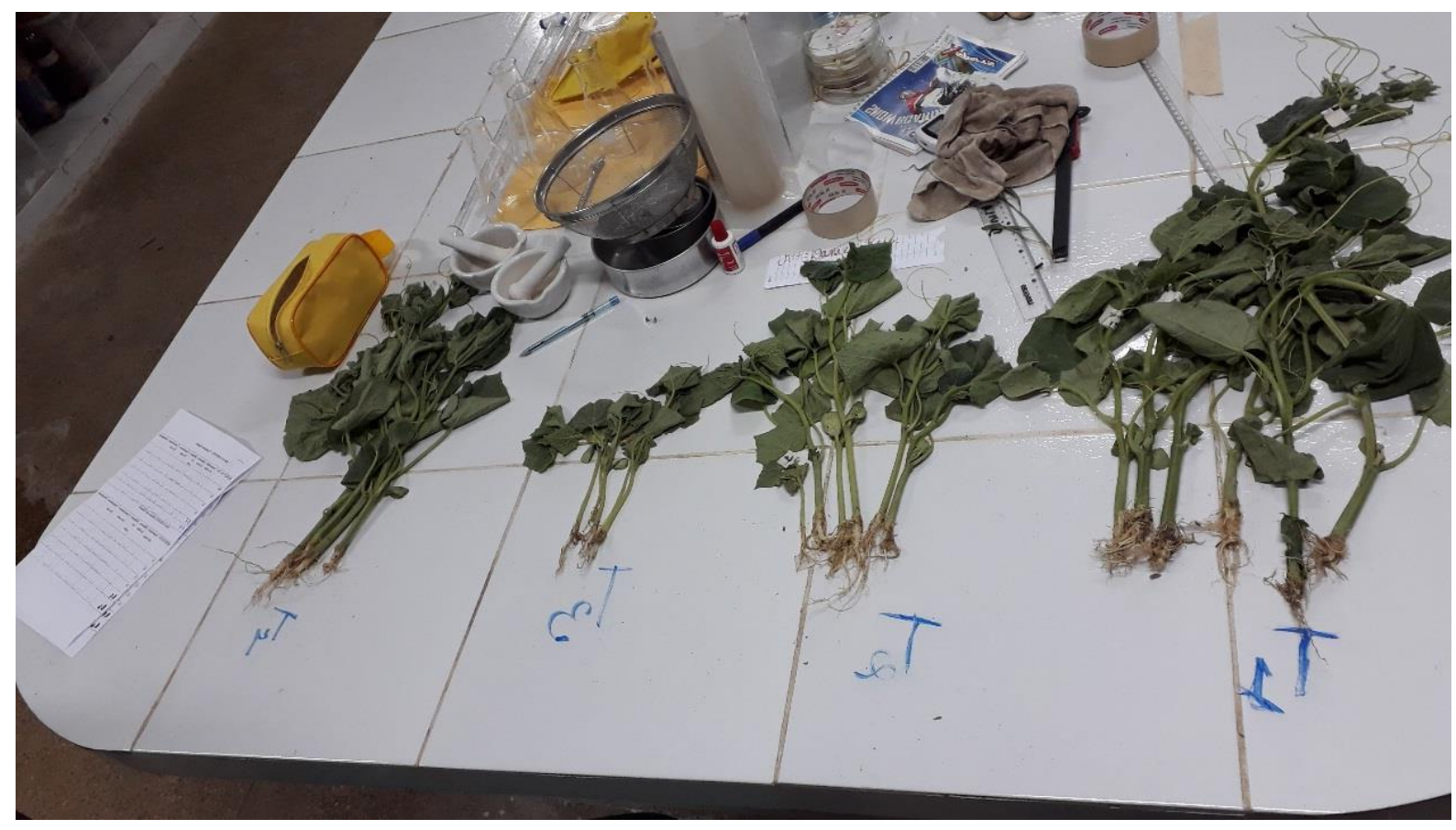

Fig 7:Analise após 35 dias Fonte: Própria

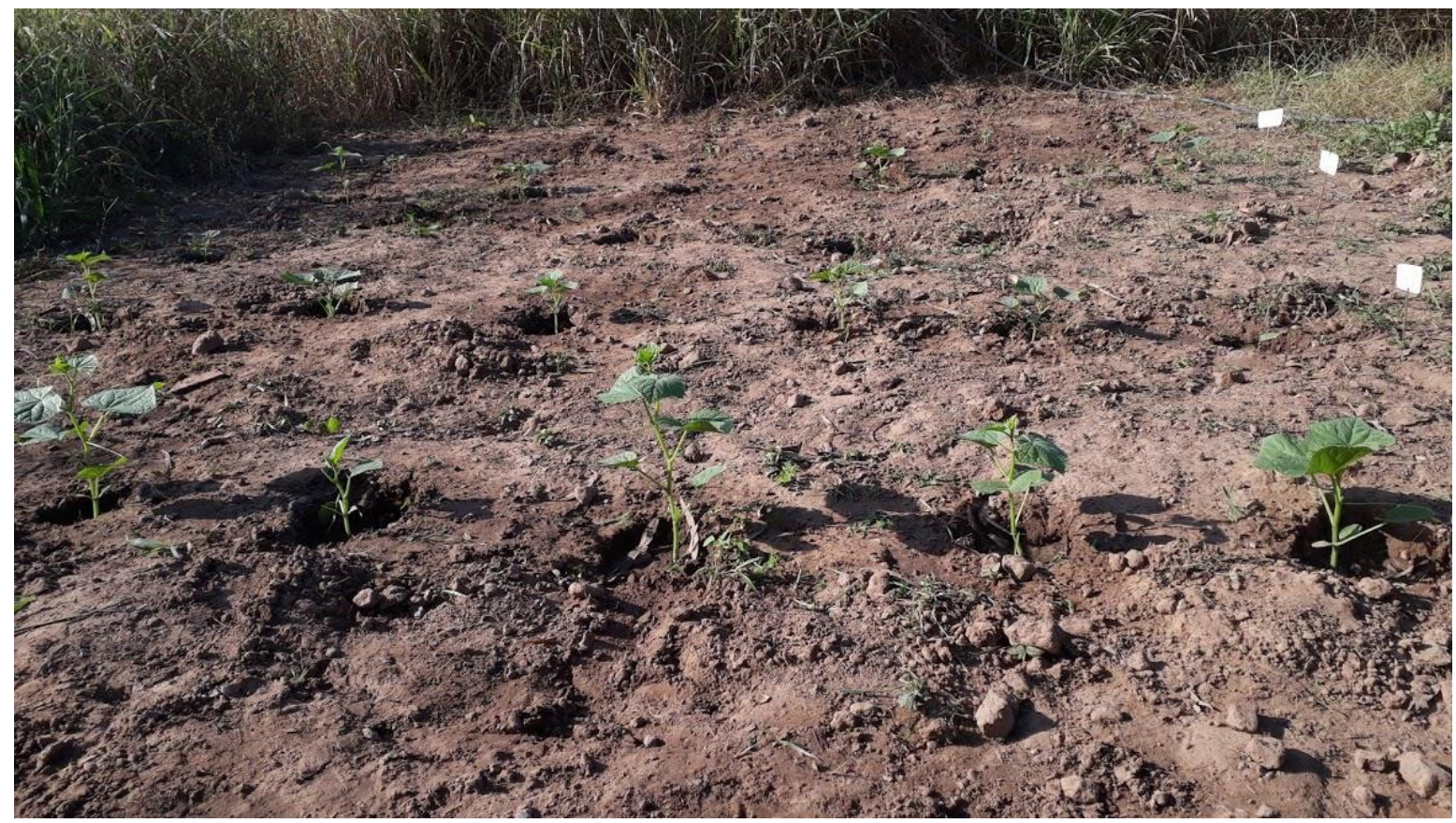

Fig.8: Plantas centrais. Fonte: Própria 


\section{RESULTADOS E DISCUSSÕES}

\section{Tabela 1: Médias do desenvolvimento do pepino nos diferentes substratos}

\begin{tabular}{|c|c|c|c|c|c|c|}
\hline Tratamentos & $\begin{array}{l}\text { Quant. } \\
\text { de } \\
\text { folhas }\end{array}$ & $\begin{array}{l}\text { Diam. } \\
\text { da } \\
\text { raiz }\end{array}$ & $\begin{array}{l}\text { Diam. } \\
\text { do } \\
\text { caule }\end{array}$ & $\begin{array}{c}\text { Compr. } \\
\text { da } \\
\text { raiz }\end{array}$ & $\begin{array}{l}\text { ompr. } \\
\text { da } \\
\text { caule }\end{array}$ & Brotamento \\
\hline Comp. Orgânico & $6.66667 \mathrm{a}$ & $8.61667 \mathrm{a}$ & $4.61667 \mathrm{a}$ & $42.00000 \mathrm{ab}$ & $3.75000 \mathrm{ab}$ & $383333 \mathrm{a}$ \\
\hline Humus de Palmeira & $4.16667 \mathrm{bc}$ & $4.76667 \mathrm{bc}$ & $2.86667 \mathrm{ab}$ & $20.83333 \mathrm{~b}$ & $4.66667 \mathrm{a}$ & $1.66667 \mathrm{~b}$ \\
\hline Esterco de bode & $2.66667 \mathrm{c}$ & $2.23333 \mathrm{c}$ & $1.55000 \mathrm{~b}$ & $13.41667 \mathrm{~b}$ & $2.91667 \mathrm{~b}$ & $1.33333 \mathrm{~b}$ \\
\hline Testemunha & $5.00000 \mathrm{ab}$ & $5.33333 \mathrm{~b}$ & $4.25000 \mathrm{ab}$ & b. $\quad 30.16667 \mathrm{ab}$ & $2.91667 \mathrm{~b}$ & $3.83333^{\mathrm{a}}$ \\
\hline
\end{tabular}

Médias seguidas de mesma letra na coluna não diferem entre si, pelo teste de Tukey

Pela tabela 1 apresentada pode-se observar que tratamento T1 (composto orgânico) o desenvolvimento foi superior aos demais tratamentos em todos os aspectos avaliados, em relação ao T3 (Esterco de bode), o qual apresentou o pior desenvolvimento. Os tratamentos T2 ( Humus de palmeira) e T4 ( testemunha) foram relativamente igualitários pelo teste $\mathrm{F}$, ou seja, dentro dos 35 dias que ficaram sob avaliação.

Segundo o autor Do Nascimento et al., (2005) O melhor desempenho do T1 em relação aos demais pode ser explicado devido algumas vantagens da compostagem, pois influencia na "melhoria da saúde do solo". A matéria orgânica composta se liga às partículas (areia, limo e argila), ajudando na retenção e drenagem do solo melhorando sua aeração; aumenta a capacidade de infiltração de água, reduzindo a erosão; dificulta ou impede a germinação de sementes de plantas invasoras. Ressalta-se que os fertilizantes orgânicos e os compostos orgânicos em geral, além de melhorar as propriedades físicas e físico-químicas do solo, contribuem para o combate aos nematoides que causam inúmeros prejuízos ao pepino e outras hortaliças.

De acordo com os estudos feitos por Petersen at al., (1998) Os estercos de caprinos e ovinos, por possuírem uma espécie de membrana que os revestem e tornam-os duros quando excretados, 
possuem uma maior resistência à decomposição, pois a velocidade de decomposição e consequente mineralização dos resíduos orgânicos interferem diretamente na disponibilidade de nutrientes para as plantas, segundo esse estudo feito por Petersen pode-se explicar o pior desempenho do tratamento 3 nos dias que ficou sob avaliação. Uma grande diferença de desempenho entre os dois tratamentos T1 e T3 observa-se na ( Fig. 9 e 10) ainda em campo dentre os dias que ficaram sob avaliação.

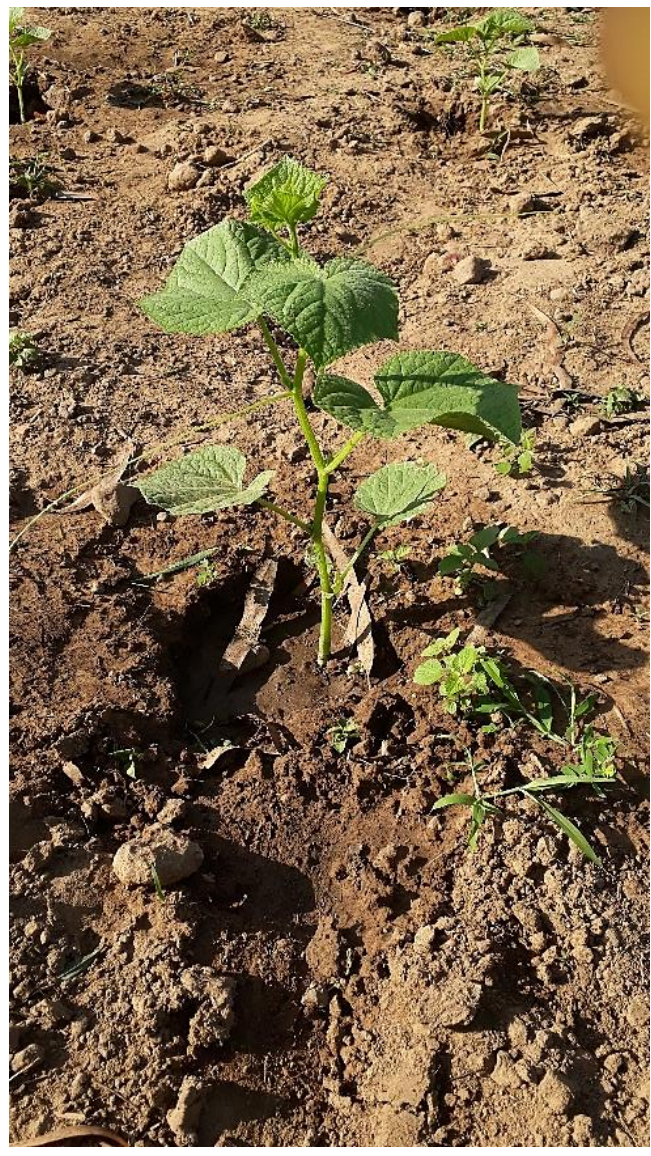

Fig: 9 Tratamento 1. Fonte: Própria

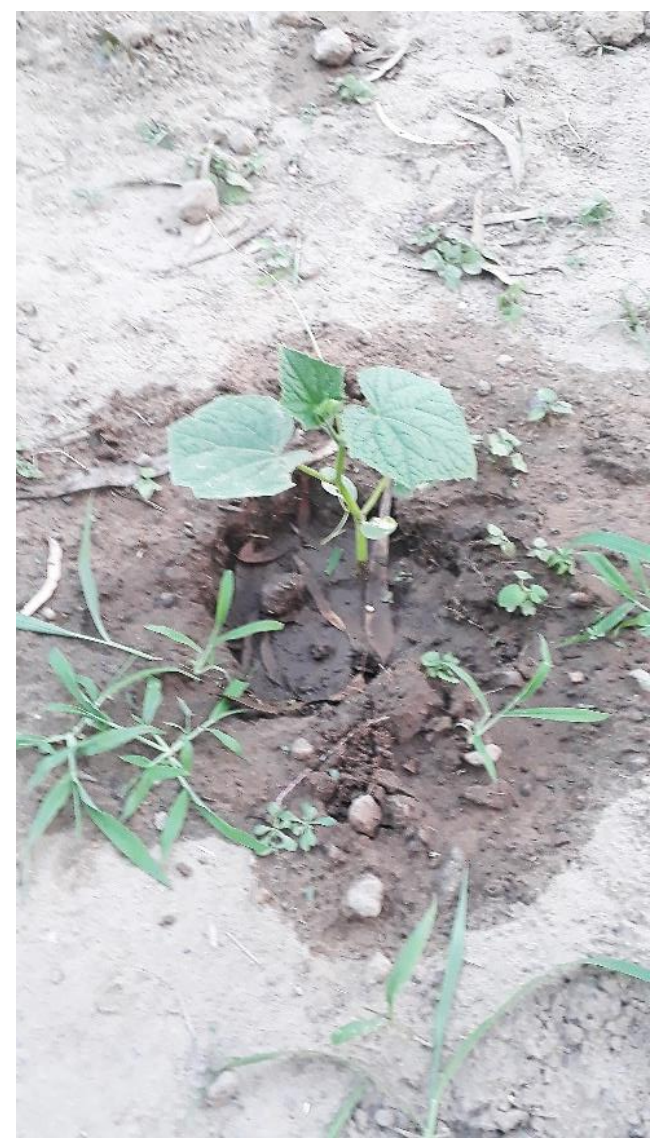

Fig: 10 Tratamento 3. Fonte: Própria

\section{CONCLUSÃO}

A compostagem pode ser considerada um processo satisfatório do ponto de vista tecnológico para tratamento dos resíduos, através deste processo, se obtêm uma estabilização acelerada do material e homogeneização viabilizando o aproveitamento de resíduos gerados. Do ponto de vista agronômico, este processo tem uma grande importância, pois uma quantidade considerável de nutrientes estará retornando para o solo na forma mineral e orgânica, proporcionando melhorias 
químicas, físicas e biológicas. Esse processo também aborda fatores econômicos e sociais com o intuito de reduzir desperdícios alimentares provenientes do restaurante do IFMA campus Codó. 


\section{REFERENCIAS}

CARVALHO, A. D. F. de; AMARO, G. B.; LOPES, J. F.; VILELA, N. J.;MICHEREFF FILHO, M.; ANDRADE, R. 2013. ; 18 p.

CAÑIZARES, K. A. L.; GOTO, R. Crescimento e produção de híbridos de pepino em função da enxertia. Horticultura Brasileira, Brasília, DF, v. 16, n. 2, p. 110-113, 1998. www.scielo.br/pdf/hb/v19n3/v19n3a10

EMBRAPA. Minhocultura. Disponível em: <http://www.embrapa.gov.br/.2007.(acessado em 20/09/2019) .

DO NASCIMENTO, Adelina M. (et. al). Química e Meio Ambiente: Reciclagem de lixo e química verde: papel, vidro, pet, metal, orgânico. Secretaria de Educação: Curso Formação Continuada Ciências Da Natureza, Matemática E Suas Tecnologias, 2005.

FILGUEIRA FAR. 2008. Novo manual de olericultura: agrotecnologia moderna na produção e comercialização de hortaliças. Viçosa: UFV. 421p.

FNP Consutoria \& Comércio. Agrianual 2000. São Paulo, 2000. 546p.

GOULART, R. M. M. Desperdício de alimentos: um problema de saúde pública. Integração, v.54, n.1. 2008.

NOMURA, E. S.; CARDOSO, A. I. I. Redução da área foliar e o rendimento do pepino japonês. Scientia Agricola, v. 57, n. 2, p. 257-261, 2000.

MANO, E.B. et al. Meio Ambiente, Poluição e Reciclagem. 2ªEd. São Paulo: Blucher, 2010. 182 p.

OLIVEIRA E. C. A; SARTORI R. H; GARCEZ. T. B. Compostagem. Piracicaba. São Paulo: 2008.

PETERSEN SO; LIND AM; SOMMER SG. 1998. Nitrogen and organic matter losses during storage of cattle and pig manure. Journal of Agricultural Science 130: 69-79.

RICARTE M. P. R; MOURA FÉ M. A. B; SANTOS I. H. V. S; LOPES A. K. M. SABER CIENTÍFICO, Porto Velho, 1 (1): 158 - 175, jan./jun.,2008.

SILVA JUNIOR, E.; TEIXEIRA, R. P. A. Manual de procedimentos para utilização de sobras alimentares. 2007, disponível em<http://www.sescsp.org.br/sesc/mesabrasilsp/biblioteca/Manual_Procedimentos_Utili zacao_Sobras.doc>. Acesso em: 13 março. 2019.

SOUZA, F.A. de; AQUINO, A.M. de; RICCI, M. dos S.F.; FEIDEN, A. Compostagem. Seropédida: Empresa Brasileira de Pesquisa Agropecuária - Embrapa Agrobiologia, 11 p., 2001 (Boletim Técnico, nº 50). 